\title{
PREFACE
}

\section{Emergent and Early Literacy Intervention: Etiological Perspectives}

I am extremely pleased to offer this issue guest edited by my talented and energetic colleague Laura Justice. One of the most critical issues facing children with communicative delays or disorders is how such disability affects literacy development and skills. No other aspect of academic achievement has as much impact on all areas of the curriculum and eventual vocational success.

This issue examines current research and practice considerations for optimizing the emergent and early literacy achievements of children comprised in "high-risk" groups in literacy development. To this end, eight different teams of experts provide a summary of current research on the development of literacy skills (Justice, Sofka, and McGinty), how they are best assessed (Hall, Culatta, and Black), and how they are best cultivated in typically developing children as well as in seven special populations. These particularly challenging subgroups of children include children acquiring English as a second language (Restrepo and Gray), children with specific language impairment (Schuele, Spencer, Barako, and Guillot), children with developmental apraxia of speech (Gillon and Moriarty), visually impaired children (Erickson and Hatten), hearing impaired children (Kaderavek and Pakulski), and children with multiple concurrent disabling conditions (Koppenhaver, Hendrix and Williams). Each article provides a summary of the extant literature concerning what is known about literacy development among these populations of children and summarizes the current evidence suggesting how literacy achievements for these children may be optimized.

It is noteworthy that this issue contains discussion of populations for which clinicians typically have little literature to guide them in remediation of oral and written language deficits, such as developmental apraxia, visual impairment, and multiple disabilities. Each article in this issue is crafted to provide a concise summary of most typical concerns, and the research literature to date that supports specific methods to address them. I believe that you will agree with me that it will be an invaluable clinical guide.

In asking our readers to suggest future topics for Seminars issues, we have long received feedback suggesting that working with emergent literacy for children on our caseloads is an ever growing concern. I firmly believe that the articles in this volume will greatly assist in addressing this important area of practice. As always, I look forward to your feedback and suggestions for future issues that you would like Seminars to address, whether it be a topic we have not yet addressed or one that you would like to see updated with current best practice suggestions. You can make these suggestions on the self-assessment forms in the back of this issue or email me at nratner@hesp.umd.edu.

Nan Bernstein Ratner, Ed.D. Co-Editor in Chief ${ }^{1}$

\footnotetext{
${ }^{1}$ Professor and Chairman, Department of Hearing and Speech Sciences, University of Maryland, College Park, Maryland.

Emergent and Early Literacy Intervention: Etiological Perspectives; Guest Editor, Laura Justice, Ph.D.
}

Semin Speech Lang 2007;28:1-2. Copyright (C) 2007 by Thieme Medical Publishers, Inc., 333 Seventh Avenue, New York, NY 10001, USA. Tel: +1(212) 584-4662.

DOI 10.1055/s-2007-967924. ISSN 0734-0478. 